COMUNICAÇÃOCIENTÍFICA

\title{
MEIO DE CULTURA, CONCENTRAÇÃO DE AIB E TEMPO DE CULTIVO NO ENRAIZAMENTO IN VITRO DE AMOREIRA-PRETA E FRAMBOESEIRA ${ }^{1}$
}

\author{
LUCIANE NOLASCO LEITZKE² ${ }^{2}$ CLÁUDIA ROBERTADAMIANI ${ }^{3}$, MÁRCIA WULFF SCHUCH $^{4}$
}

RESUMO- A propagação da amoreira-preta e da framboeseira dá-se principalmente por meio de estacas de raiz e mesmo de hastes novas, contudo, já é crescente o interesse pelo uso da micropropagação como um método alternativo de propagação . O enraizamento é uma das etapas mais difícieis, onde a definição do meio de cultivo, da concentração ótima de AIB para o enraizamento, constitui um passo importante, por isso objetivou-se com este experimento determinar o melhor meio de cultivo, melhor tipo de cultivo e a melhor concentração de AIB no meio de cultura para o enraizamento in vitro da amoreira-preta 'Xavante' e de framboeseira 'Batum' e 'Heritage'. O material vegetal utilizado foram microestacas apicais com duas folhas, com cerca de $1 \mathrm{~cm}$ de comprimento, oriundas do cultivo in vitro. Os fatores estudados foram o tipo de meio de cultura MS e WPM - Wood Plant Media, a concentração de AIB no meio de cultura e o tempo de cultivo das microestacas em meio com AIB. O meio WPM, em concentrações baixas, menores de $3 \mu \mathrm{M}$ de AIB, induziram maiores médias de enraizamento e comprimento. Concentrações altas de AIB induziram a formação de calo, para amoreira-preta, 'Xavante'. Para a framboeseira o meio WPM, com menores concentrações de AIB $(0$ e $3 \mu \mathrm{M})$, mostrou as melhores médias no número de raízes, comprimento de raízes e pequena intensidade de calo; com as maiores concentrações de AIB, ocorreu maior aparecimento de calo.

Termos para indexação: propagação in vitro; pequenas frutas; Rubus spp.

\section{CULTURE ENVIRONMENT, IBA CONCENTRATION AND CULTIVATION TIME ON IN VITRO ROOTING OF BLACKBERRY AND RASPBERRY}

\begin{abstract}
The propagation of blackberry and raspberry occur mainly through root cutting and even of softwoods stem; however, it is already increasing the interest for the use of the micropropagation as an alternative technique of vegetative propagation of fruit plants, since the rooting is one of the most difficult stages, in which the definition of both the culture environment and the best concentration of AIB for the rooting, is an important stage. For that purpose, the aim of this research was to determine the best cultivation type and the best concentration of IBA in the culture environment for the in vitro rooting of the blackberry 'Xavante' and the raspberry 'Batum' and 'Heritage'. The vegetable material used was atex microcutting with two leaves, measuring about $1 \mathrm{~cm}$ of length, originated from the in vitro cultivation. The studied factors were the kinds of culture (MS and WPM), the IBA concentration in the culture environment and the time of cultivation of the microcutting in an environment with IBA. The WPM environment, in low concentrations, less than $3 \mu \mathrm{M}$ of IBA, together with T1, induced larger rooting averages and length. High concentrations of AIB induced the callus formation for blackberry 'Xavante'. For raspberry, using WPM environment with smaller concentrations of AIB $(0$ and $3, \mu \mathrm{M})$, it was shown the best average in the number of roots, length of roots and small callus intensity, with the largest concentrations of IBA it happened larger callus emergence. Index Terms: in vitro propagation; berries; Rubus sp; Rubus idaeus.
\end{abstract}

\footnotetext{
'(Trabalho 165-08). Recebido em: 18-06-2008. Aceito para publicação em: 16-02-2009.

${ }^{2}$ Engenheira Agrônoma, M. Sc., Doutoranda do Programa de Pós-Graduação em Agronomia, área de concentração em Fruticultura de Clima Temperado, FAEM/UFPel. Rua: Santa Cruz, 2096 ap:201, 96015-710 - Centro, Pelotas-RS. E-mail: lucianeleitzke@gmail.com Bolsista CNPQ.

${ }^{3}$ Bióloga, Dra. Bolsista DTI - CNPq. Email: claudami2004@yahoo.com.br

${ }^{4}$ Engenheira Agrônoma, Dra., Professora do Departamento de fitotecnia, FAEM/UFPel. Caixa Postal 354, 96010-900, Pelotas-RS. E-mail: marciaws@ufpel.tche.br
} 
O cultivo da amoreira-preta e da framboeseira é uma boa opção para diversificação de pequenas propriedades, por serem espécies rústicas e de alta produtividade (Antunes \& Raseira, 2004) (Raseira et al., 2004).

As pequenas frutas ocupam espaço crescente no elenco de espécies frutíferas em várias regiões do mundo. No Brasil, amoras e framboesas despertam a atenção de produtores, por se tratar de uma alternativa de diversificação potencialmente rentável, e dos consumidores, por serem componentes de uma dieta saudável.

A propagação dessas espécies ocorre principalmente por meio de estacas herbáceas de 15 a $20 \mathrm{~cm}$, rebentos e hastes novas. Embora esses métodos tradicionais sejam comumente usados, a técnica de cultura de tecidos pode eventualmente, tornar-se um método mais promissor de propagação (Caldwell, 1984), permitindo a obtenção de inúmeras plantas isentas de vírus, geneticamente uniformes e em curto espaço de tempo (Pasqual et al., 1991), representando um método alternativo de propagação vegetativa para essas espécies.

O controle do desenvolvimento de raízes adventícias é influenciado por diversos fatores, entre os quais reguladores de crescimento, alguns promovendo, outros inibindo o enraizamento (Assis \& Teixeira, 1998). As auxinas compreendem uma grande família de substâncias que têm em comum a capacidade de produzir crescimento celular e também promover a divisão celular em cultura de tecidos (Krikorian, 1991). As auxinas têm sido utilizadas na estimulação de raízes adventícias. Entre elas, o AIB tem sido bastante usado por não causar fitotoxicidade aos explantes em uma larga faixa de concentração e ser eficiente em uma grande variedade de espécies (Hartmann et al., 1997).

A vantagem deste tipo de enraizamento é o melhor controle das condições em que se trabalha e, com isso, a obtenção de um alto percentual de enraizamento, sendo uma das etapas mais difíceis da propagação. O tipo de meio de cultura, de auxina e suas concentrações são as variáveis que, em geral, mais influenciam no enraizamento, e variam conforme a espécie e a cultivar. Quando a concentração de auxina no meio é excessiva, ocorre formação de calo na base do explante, comprometendo a rizogênese e o crescimento da parte aérea. Por esta razão recomenda-se, a utilização de dois meios de cultura para a rizogênese. Primeiramente, as partes aéreas permanecem em meio com auxina, favorecendo a indução e, posteriormente, são transferidas para meio sem auxina, estimulando, assim, a rizogênese e o crescimento das raízes. Este processo tem sido adotado com frequência em espécies lenhosas florestais e frutíferas (Fett Neto et al., 1992). O enraizamento in vitro do porta-enxerto de marmeleiro 'A' foi obtido por Dolcet-Sanjuan et al. (1991), cultivando os brotos em meio de cultura contendo 5 M de ANA durante uma semana, e, em seguida, transferindo-os para meio de cultura sem auxina durante quatro semanas.

Assim, objetivou-se com este trabalho determinar o melhor meio de cultivo, a melhor concentração de AIB no meio e o tempo de cultivo de microestacas para o enraizamento in vitro de Rubus spp. 'Xavante' e Rubus idaeus L. 'Batum'.

O trabalho foi conduzido no Laboratório de Micropropagação de Plantas Frutíferas, do Departamento de Fitotecnia da Faculdade de Agronomia Eliseu Maciel (FAEM), da Universidade Federal de Pelotas (UFPel), em Pelotas-RS, constituído de dois experimentos, um com amoreirapreta e um com framboeseira.

O material vegetal utilizado no experimento foram microestacas apicais, de amoreira-preta 'Xavante' e de framboeseira 'Batum', com duas folhas e aproximadamente 1 a 1,5 cm de comprimento, oriundas do cultivo in vitro. Os fatores estudados foram o tipo de meio de cultura [MS (Murashige \& Skoog, 1962) e WPM - Wood Plant Medium (Lloyd \& Mccown, 1980)]; a concentração de AIB no meio de cultura $(0 ; 3 ; 6 ; 9$ e $12 \mu \mathrm{M})$ e o tempo de cultivo das microestacas em meio com AIB T1 = uma semana em meio com AIB + três semanas em meio sem AIB ou $\mathrm{T} 2$ = quatro semanas em meio com AIB), no delineamento inteiramente casualizado, em esquema fatorial $5 \times 2 \times 2$, totalizando vinte tratamentos com quatro repetições. Cada repetição foi constituída de um frasco com cinco explantes. Utilizou-se para os meios de MS e WPM, $30 \mathrm{~g} \mathrm{~L}^{-1}$ de sacarose, $100 \mathrm{mg} \mathrm{L}^{-}$ ${ }^{1}$ de mioinositol e $6 \mathrm{~g} \mathrm{~L}^{-1}$ de ágar, sendo o $\mathrm{pH}$ ajustado para 5,8, antes da inclusão do ágar e, posteriormente, autoclavado a $121^{\circ} \mathrm{C}$ e $1,5 \mathrm{~atm}$, por 20 minutos.

Após a inoculação, os explantes foram mantidos em sala de crescimento com temperatura de $25 \pm 2{ }^{\circ} \mathrm{C}$, luminosidade de $27 \mu$ mols. $\mathrm{m}^{-2} . \mathrm{s}^{-1} \mathrm{e}$ fotoperíodo de 16 horas.

Após 30 dias, foram avaliadas as variáveis: porcentagem de enraizamento, número médio de raízes e comprimento das raízes. Os dados dos dois experimentos foram submetidos à análise de variância, pelo teste $\mathrm{F}$, e as médias dos tratamentos, comparadas estatisticamente pelo teste de Duncan, e a regressão polinomial, através do programa estatístico WinStat (Machado \& Conceição, 2002). 
No primeiro ensaio, observou-se efeito significativo para as variáveis porcentagem de enraizamento, número médio de raízes e comprimento médio das raízes, havendo diferença significativa para o fator meio de cultura. $\mathrm{O}$ meio WPM foi o que apresentou as melhores médias para as variáveis analisadas (Tabela 1). No entanto, Karakullukçu et al. (1993) obtiveram 87\% de enraizamento de amoreira em meio de cultura MS sem reguladores de crescimento. Centellas et al. (1999) também obtiveram enraizamento in vitro de macieira 'Fred Hough' em meio de cultura MS, porém com a concentração de sais reduzida para $50 \%$ e com a adição de $3 \mu \mathrm{M}$ de AIB.

Welander (1985), Ramirez del Castillo e Angarita Zerda (1990) obtiveram resultados positivos com a diluição dos macronutrientes no meio de cultura de enraizamento in vitro de Rubus spp. Os autores obtiveram $100 \%$ de êxito no enraizamento com os macronutrientes do meio de cultura diluídos a 1/5 e com acréscimo de $\operatorname{AIB}(0,01$ $\left.\mathrm{mg} \mathrm{L}^{-1}\right)$.

Para a variável comprimento médio das raízes, houve diferença significativa para o fator tempo de cultivo das microestacas em meio com AIB (Tabela 2). Em explantes que permaneceram por uma semana em meio com AIB, foram obtidas melhores médias em relação aos que permaneceram em meio com AIB por quatro semanas. Soares et al. (2006) quando transferiram os explantes de mirtilo para meio sem AIB, observaram maior comprimento das raízes.

Para o comprimento médio das raízes, observou-se comportamento quadrático para o fator concentração de AIB (Figura 1). Com o aumento da concentração de AIB, houve redução do comprimento das raízes representado por uma curva quadrática, até a concentração de $2,5 \mu \mathrm{M}$ de AIB. Hoepfner et al. (1996) detectaram uma associação positiva entre as baixas concentrações de reguladores de crescimento e a alta porcentagem de enraizamento de amoreira.

Radmann et al. (2000) não observaram diferença significativa na taxa de enraizamento em amoreira-preta 'Ébano' em meio de cultura com diferentes concentrações de AIB, variando entre 0 a $1 \mu \mathrm{M}$.

Ramirez del Castillo e Angarita Zerda (1990) também observaram que a ausência de reguladores de crescimento ou concentração muito baixa de auxinas são recomendadas para induzir raízes em espécies de Rubus. Dantas et al. (2000) obtiveram o melhor enraizamento da amoreira-preta 'Caingangue' no meio de cultura sem a auxina ANA. Hartmann et al. (1997) concluem que o tratamento com auxinas deve ser usado somente em espécies de difícil enraizamento. Quando a espécie é de fácil enraizamento, como o caso da amoreira-preta, não há justificativa para o gasto adicional com auxinas.

No segundo ensaio, observou-se que, nas variáveis porcentagem de enraizamento, número médio de raízes e comprimento médio das raízes, houve diferenças significativas para a interação entre tipo de meio e o tempo de cultivo das microestacas no meio. Independentemente do meio de cultura, o tempo de cultivo que propiciou melhores resultados foi aquele em que o material vegetal foi mantido por uma semana em meio de cultura com AIB (Tabela 3 ).

Soares et al. (2006) verificaram maiores porcentagens de enraizamento em explantes tratados com AIB por uma semana seguido da transferência para meio livre de hormônio em mirtilo ‘Georgia Gem', concordando com o resultado do presente trabalho. Mackay (1996), estudando o enraizamento in vitro de Arbutus xalapensis, uma espécie ornamental da família Ericaceae, verificou que microestacas tratadas com $6,1 \mu \mathrm{M}$ AIB suplementado ao meio de cultura por uma semana, seguido da transferência para meio livre de AIB por quatro semanas, apresentaram uma porcentagem de enraizamento de $83 \%$. Ostrolukcá et al. (2004), trabalhando com diferentes cultivares de mirtilo, obtiveram cerca de 80 a $95 \%$ de enraizamento utilizando $0,8 \mathrm{mg} \mathrm{L}^{-1}$ de AIB adicionado ao meio de cultura, porém os mesmos autores ressaltam que esta porcentagem varia entre cultivares.

Observou-se um comportamento quadrático no tratamento T1, em função dos níveis de AIB no que diz respeito à porcentagem de enraizamento de framboeseira 'Batum' (Figura 2). Os melhores resultados de percentagem de enraizamento foram obtidos até a concentração de $6,5 \mu \mathrm{M}$, depois se observa uma queda na porcentagem de enraizamento de acordo com o aumento da concentração de AIB. Para Fachinello et al. (1994), o aumento da concentração de auxinas aplicadas nos brotos provoca efeito estimulador até um certo valor, a partir do qual acréscimos maiores têm efeito inibitório. Este resultado reforça a afirmativa de Grattapaglia \& Machado (1998) de que, quando a concentração de auxina no meio de enraizamento é excessiva, ocorre o comprometimento da rizogênese.

Já para o tratamento T2, observou-se comportamento quadrático, havendo uma queda na porcentagem de enraizamento até a concentração de 7,5 $\mu \mathrm{M}$, com posterior aumento da porcentagem de enraizamento, em função do aumento da concentração de AIB.

García \& González (1992) obtiveram 77 a 100\% de enraizamento em Rubus sem a necessidade de 
adição de reguladores de crescimento para o enraizamento. Hoepfner et al. (1996) também detectaram uma associação positiva entre as baixas concentrações de reguladores de crescimento e a alta porcentagem de enraizamento de amoreira.

O meio WPM adicionado de AIB, em baixas concentrações, é o melhor meio de enraizamento para amoreira-preta 'Xavante', sendo suficiente a adição de 2,5 $\mu \mathrm{M}$ ao meio de cultura e mantido uma semana, seguido do cultivo em meio livre de regulador de crescimento.

Para framboeseira 'Batum', o meio MS adicionado de $6,5 \mu \mathrm{M}$ de AIB ao meio de cultura e mantido uma semana, seguido do cultivo em meio livre de regulador de crescimento, é suficiente para o enraizamento in vitro da espécie.

TABELA 1 - Porcentagem de enraizamento, número de raízes e comprimento das raízes de amoreira-preta 'Xavante' em função do tipo de meio de cultura utilizado. Pelotas-RS, 2007.

\begin{tabular}{cccc}
\hline Tipo de meio & Enraizamento (\%) & Número de raízes & Comprimento das raízes \\
\hline WPM & $81,5 \mathrm{a}$ & $3,39 \mathrm{a}$ & $1,47 \mathrm{a}$ \\
MS & $52 \mathrm{~b}$ & $1,63 \mathrm{~b}$ & $0,85 \mathrm{~b}$ \\
CV $(\%)$ & 42,90 & 27,45 & 67,41
\end{tabular}

Médias seguidas da mesma letra minúscula nas colunas não diferem entre si, pelo teste de Duncan, ao nível de $5 \%$ de probabilidade de erro.

TABELA 2 - Comprimento das raízes de microestacas de amoreira-preta 'Xavante' em função do tempo de cultivo. Pelotas-RS, 2007.

\begin{tabular}{cc}
\hline TEMPO DE CULTIVO DAS MICROESTACAS & MÉDIAS* \\
\hline 7 dias com AIB + 21 dias sem AIB & $1,39 \mathrm{a}$ \\
28 dias com AIB & $0,93 \mathrm{~b}$ \\
CV $(\%)$ & 67,41 \\
\hline
\end{tabular}

Médias seguidas da mesma letra minúscula nas colunas não diferem entre si, pelo teste de Duncan, ao nível de $5 \%$ de probabilidade de erro.

TABELA 3 - Porcentagem de enraizamento, número médio de raízes, comprimento médio das raízes de framboeseira 'Batum' em função do tipo de meio de cultura e do tempo de cultivo no meio de cultura. Pelotas-RS, 2007.

\begin{tabular}{|c|c|c|c|c|c|c|}
\hline \multirow[t]{2}{*}{ Tipo de meio } & \multicolumn{2}{|c|}{$\begin{array}{c}\text { Enraizamento } \\
(\%)\end{array}$} & \multicolumn{2}{|c|}{$\begin{array}{c}\text { Número médio de } \\
\text { raízes }\end{array}$} & \multicolumn{2}{|c|}{$\begin{array}{c}\text { Comprimento médio das } \\
\text { raízes }\end{array}$} \\
\hline & T1 & $\mathrm{T} 2$ & T1 & $\mathrm{T} 2$ & $\mathrm{~T} 1$ & $\mathrm{~T} 2$ \\
\hline WPM & $64 \mathrm{aA}$ & $57 \mathrm{aA}$ & $1,73 \mathrm{aA}$ & $1,82 \mathrm{aA}$ & $0,593 \mathrm{aB}$ & $0,820 \mathrm{aA}$ \\
\hline MS & $54 \mathrm{aA}$ & $9 \mathrm{bB}$ & $1,36 \mathrm{aA}$ & $0,14 \mathrm{bB}$ & $0,421 \mathrm{aA}$ & $0,09 \mathrm{bB}$ \\
\hline CV (\%) & \multicolumn{2}{|c|}{55,79} & \multicolumn{2}{|c|}{27,96} & \multicolumn{2}{|c|}{71,14} \\
\hline
\end{tabular}

Médias seguidas da mesma letra, maiúscula nas linhas e minúscula nas colunas, não diferem entre si, pelo teste de Duncan, ao nível de $5 \%$ de probabilidade de erro.

$(\mathrm{T} 1$ = uma semana em meio com AIB + três semanas em meio sem AIB, T2 = quatro semanas em meio com AIB) 


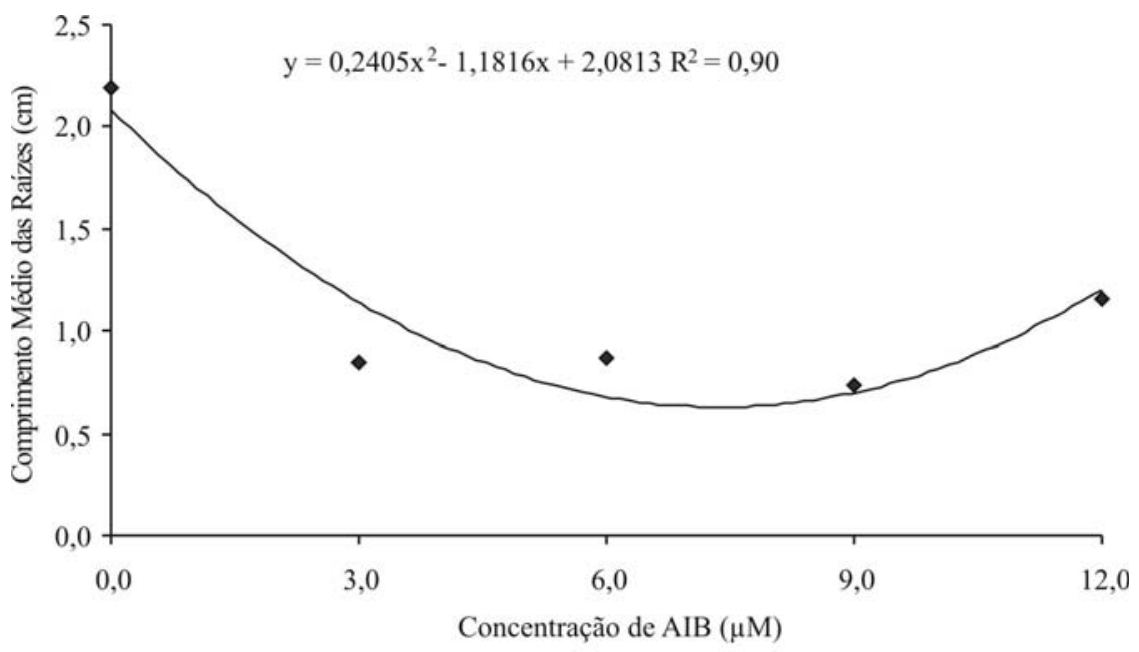

FIGURA 1 - Comprimento médio de raízes de amoreira-preta 'Xavante' em função de diferentes concentrações de AIB. Pelotas-RS, 2007.

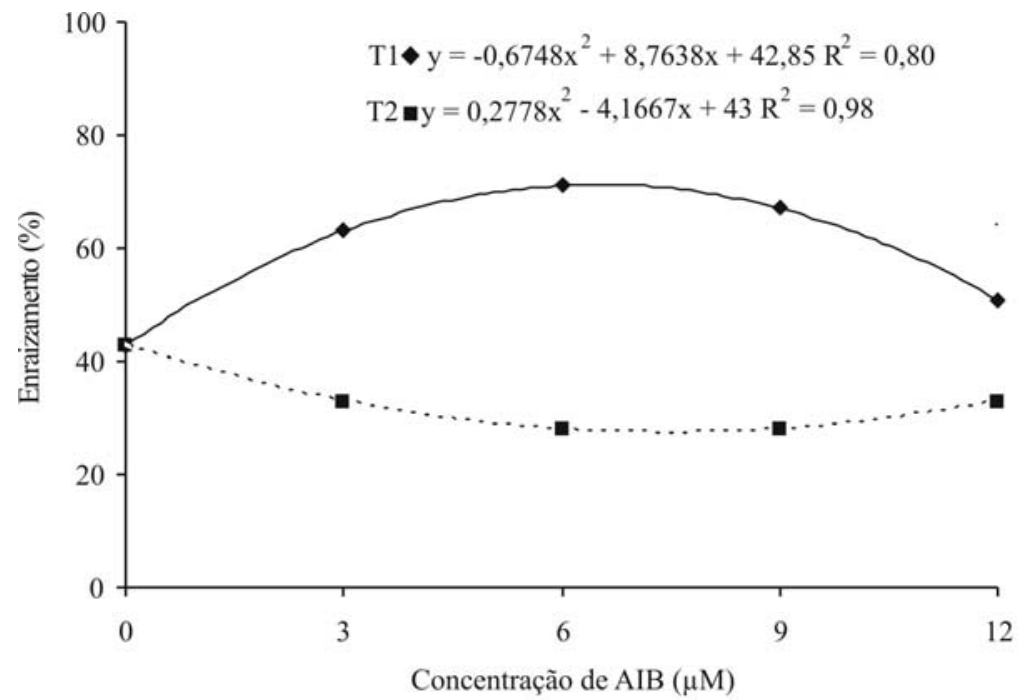

FIGURA 2 - Porcentagem de enraizamento de framboeseira 'Batum' em função da concentração de AIB e do tempo de cultivo das microestacas no meio, $(\mathrm{T} 1=$ uma semana em meio com AIB + três semanas em meio sem AIB, T2 = quatro semanas em meio com AIB). Pelotas-RS, 2007.

\section{REFERÊNCIAS}

ANTUNES, L.E.C.; RASEIRA, M.C.B. Aspectos técnicos da cultura da amora-preta. Pelotas-RS: Embrapa Clima Temperado, 2004, p. 54. (Documento, 122)

ASSIS, T.F.; TEIXEIRA, S.L. Enraizamento de Plantas Lenhosas, In: TORRES, A.C.; CALDAS, L.S.; BUSO, J.A. Cultura de tecidos e transformação genética de plantas. Brasília: Embrapa - SPI /CNPH, 1998. v.1, p.183-260.
CALDWELL, J.D. Blackberry propagation. HortScience, Alexandria, v.19, n.22, p.13-15,1984.

CENTELLAS, A.Q.; FORTES, G.R.L.; MÜLLER, N.T.G.;ZANOL, G.C.; FLORES, R.; GOTTINARI, R.A. Efeito de auxinas sintéticas no enraizamento in vitro da macieira. Pesquisa Agropecuária Brasileira, Brasília, v.34, n.2, p.181-186, 1999.

DANTAS, M. C. A.; CERETTA, M.; COUTINHO, F.E.; FORTES, G. R. de L. Enraizamento in vitro da amoreira-preta (Rubus sp.), cultivar Caigangue. Agropecuária de Clima Temperado. Pelotas, v. 3, n. 2, p.123-130, 2000. 
DOLCET-SANJUAN, R.; MOK, D.W.S.; MOK, M.C. Plantlet regeneration from cultured leaves of Cydonia oblonga L. (quince). Plant Cell Reports, New York, v.10, p.240-242, 1991.

FACHINELLO, J.C.; HOFFMANN,A.; NACHTIGAL, J.C.; KERSTEN, E.; FORTES, G.R. de L. Propagação de plantas frutíferas de clima temperado. Pelotas: UFPel, 1994. 179p.

FETT-NETO, A.G.; TEIXEIRA, S.; SILVA, E.A.M.; SANTANNA, R. . Biochemical and morphological changes during in vitro rhizogenes in cuttings of Sequoia sempervirens (D. Don) Endl. Journal of Plant Physiology, Stuttgart, v.140, p.720-728, 1992.

GARCÍA, E. A.; GONZÁLEZ,A. M. C. Enraizamento ex vitro de cuatro cultivares de zarzamora (Rubus spp.). Revista Chapingo, Chapingo, v.16, n. 8, p. 107 109, 1992.

GRATTAPAGLIA, D.; MACHADO, M.A. Micropropagação. In: TORRES, A.C.; CALDAS, L.S.; BUSO, J.A. Cultura de tecidos e transformação genética de plantas. Brasília: Embrapa - SPI / Embrapa-CNPH, 1998. v,1, p,183-260.

HARTMANN, H. T.; KESTER, D. E.; DAVIES, F. T.; GENEVE, R. L. Plant propagation: principles and practices. 6 ed. New Jersey: Prentice Hall, 1997. p. 549-622.

HOEPFNER, A. S.; NESTBY, R.; NYBOM, H. Genetic deviation initiated byadventitious shoot regeneration from tissue cultured red raspberry. Journal of_Horticultural Science. Ashford, v. 71, n. 1, p. 71-79, 1996.

KARAKULLUKÇU, S.; AGAOGLU, Y. S.; ABAK, K. Effect of different auxin-cytokinin combinations on the in vitro propagation of raspberry cv. Schonemann. Acta Horticulturae, Wageningen, $\mathrm{n}$. 352, p. 127-132, 1993.

KRIKORIAN, A. D. Medios de cultivo: generalidades, composición y preparación. In:ROCA, W. R.; MROGINSKI, L. A. Cultivo de tejidos en la agricultura: fundamentos y aplicaciones. Cali, Colombia: Centro Internacional de Agricultura Tropical, 1991.p. 41-78.

LLOYD, G.; McCOWN, B. Commercially-feasible micropropagation of mountain laurel, Kalmia latifolia, by use of shoot-tip culture. Combined Proceedings International Plant Propagators Society, Seattle, v.30, p.421-427, 1980.
MACHADO, A.; CONCEIÇÃO, A.R. Programa estatístico WinStat: sistema de análise estatístico para Windows, versão 2.0. Pelotas-RS, 2002.

MACKAY, W.A. Micropropagation of Texas madrone, Arbutus xalapensis H.B.K. HortiScience, Alexandria, v. 31, n. 6, p. 028-1029, 1996.

MURASHIGE, T.; SKOOG, F. A revised medium for rapid growth and biossay with tobacco tissue cultures. Physiologia Plantarum, Copenhagen, v.15, p.473-497, 1962.

OSTROLUCKÁ, M.G.; LIBIAKOVÁ, G.; ONDRUBKOVÁ, E.; GAJDOBOVÁ, A. In vitro propagation of Vaccinium species. Acta Universitatis Latviensis, Biology, Latvia, v.676, p. 207-212, 2004.

PASQUAL, M.; PEIXOTO, P.H.P.; SANTOS, J.C. do; PINTO, J.E.B.P. Propagação in vitro da amora-preta (Rubus sp.)cv.Ébano:uso de reguladores de crescimento.Ciência e Prática, Lavras,v.15, n.3, p.282-286,1991.

RADMANN, E. B.; GONÇALVES, E. D.; FORTES, G. R. de L. Emprego de diferentes concentrações de ácido indolbutírico e do escuro no enraizamento in vitro de amoreira-preta (Rubus sp.), cv. Ébano. In: ENCONTROESTADUALDEBOTÂNICOS, 10., 2000, Ijuí-RS. Resumos...

RAMIREZ DEL CASTILLO, A.; ANGARITA ZERDA, A. Estudios preliminares para la propagacion clonal in vitro de mora (Rubus glaucus L.). Agronomía Colombiana, Bogotá, v. 7, n. 1-2, p. 17-25, 1990.

RASEIRA, M.C.B.; GONÇALVES, E.D.; TREVISAN, R.; ANTUNES, L.E.C. Aspectos Técnicos da xultura da framboeseira, Pelotas: Embrapa Clima Temperado, 2004. p.22. (Documento, 120)

SOARES, G.C.; DAMIANI, C. R.; SCHUCH, M.W. Efeito do Tempo de Exposição do AIB no Meio de Cultura no Enraizamento in vitro de Mirtilo. In: CONGRESSO DE INICIAÇÃO CIENTÍFICA, 15., ENCONTRO DE PÓS-GRADUAÇÃO, 8., 2006, Pelotas. Anais... 2006.

WELANDER, M. In vitro culture of raspberry (Rubus idaeus) for mass propagation. Journal of Horticultural Science, Ashford, v. 60, n. 4, p. 493499, 1985. 